\title{
First report of garlic virus E in Australia
}

\section{Sari Nurulita ${ }^{1}$ (D) Andrew D. W. Geering ${ }^{1} \cdot$ Kathleen S. Crew ${ }^{2} \cdot$ Stephen Harper ${ }^{2} \cdot$ John E. Thomas $^{1}$}

Received: 8 May 2020 / Accepted: 29 July 2020 / Published online: 3 August 2020

(C) Australasian Plant Pathology Society Inc. 2020

\begin{abstract}
Garlic virus E (GarVE) is reported for the first time in Australia, from four accessions in a garlic germplasm collection planted at Gatton in South East Queensland. The presence of the virus was confirmed by reverse transcriptase PCR using GarVE-specific primers, followed by direct sequencing of the PCR product. The isolates had 99.1-99.7\% nucleotide identity to each other, and 97.9-98.5\% nucleotide sequence identity to the exemplar isolate for the species within the amplified region covering parts of the coat protein and nucleic acid binding protein genes. The distribution and economic impact of the virus in commercial plantings needs to be determined.
\end{abstract}

Keywords Allexivirus $\cdot$ Allium $\cdot$ RT-PCR $\cdot$ Sequencing

Garlic (Allium sativum L.) is prone to infection by a large number of plant viruses, particularly poty-, carla- and allexiviruses (Katis et al. 2012). It is common for garlic crops to be uniformly infected with complexes of viruses, a consequence of the fact that the plant is vegetatively propagated and infections perpetuate from one generation to the next. Worldwide, eight officially recognized allexivirus species are recorded from Allium species, namely Garlic virus A, B, $C, D, E, X$, Shallot virus $X$ and Garlic mite-borne filamentous virus (GarVA to GarVE, GarVX, ShVX and GarMbFV, respectively), although it has recently been argued that GarMbFV is not a valid species but a part of the continuum of sequence variation exhibited by GarVA (Geering \& McTaggart 2019). Allexiviruses have flexuous filamentous virions, about $800 \mathrm{~nm}$ in length and $12 \mathrm{~nm}$ in diameter, a polyadenylated single-stranded RNA genome and are transmitted by eriophyid mites such as Aceria tulipae (Kang et al. 2007). The genome of garlic virus $\mathrm{E}$ (GarVE) is $8.45 \mathrm{~kb}$ in size and contains six open reading frames, similar to all garlicinfecting allexiviruses (Chen et al. 2001).

There have been relatively few studies of viruses infecting garlic in Australia. Sward (1990) examined severely diseased

John E. Thomas

j.thomas2@uq.edu.au

1 Queensland Alliance for Agriculture and Food Innovation (QAAFI), The University of Queensland, Ecosciences Precinct, Level 2C West, GPO Box 267, Brisbane, Queensland 4102, Australia

2 Queensland Department of Agriculture and Forestry, Brisbane, Queensland, Australia plants of cv. Italian White garlic from a property in central Victoria and identified lettuce necrotic yellows virus (LNYV), leek yellow stripe virus (LYSV; referred to as garlic yellow streak virus) and a probable carlavirus based on a combination of electron microscopy, biological indexing and serological cross-reactivity. Wylie et al. (2012a, 2012b) then used a massively parallel sequencing approach to identify polyadenylated viral RNAs in a single garlic plant from a retail nursery in Perth and detected four of the allexiviruses for the first time in Australia, GarVA, -B, -C and -D, as well as the potyvirus, onion yellow dwarf virus (OYDV), and two carlaviruses, garlic common latent virus (GCLV) and shallot latent virus (SLV). In a follow-up study, Wylie et al. (2014) found various combinations of the aforementioned viruses, except LNYV, in imported bulbs from China, the USA, Mexico, Argentina and Spain. While these bulbs were intended for consumption, they retained viability when sprouted in the glasshouse. A locally grown garlic plant from Torbay in Western Australia was also included in this study and GarVX found for the first time in Australia. GarVX was also present in the some of the imported bulbs. Despite this large sequencing effort, GarVE and ShVX were not detected and are still regarded as being exotic to Australia.

As part of a larger study, plants in a garlic germplasm collection maintained in the field at the Queensland Department of Agriculture and Fisheries (DAF) Field Station at Gatton, South East Queensland $\left(27^{\circ} 32^{\prime} \mathrm{S} ; 152^{\circ} 22^{\prime}\right.$ E), containing 40 accessions of garlic, 28 originally from the World Vegetable Centre, Taiwan (previously the Asian Vegetable Research and Development Centre; AVRDC) and 12 commercial cultivars grown in Queensland, were tested for 
Fig. 1 PCR detection of garlic virus E. Expected amplicon size was 374 bp. Lane 1, 100 bp DNA ladder (Thermo Scientific); Lanes 2, 3, 4 and 5, virus isolates 5573, 5574, 5575 and 5327, respectively; Lane 6, negative control isolate 5304; Lane 7 , water control; Lane 8, 100 bp DNA ladder (Thermo Scientific)

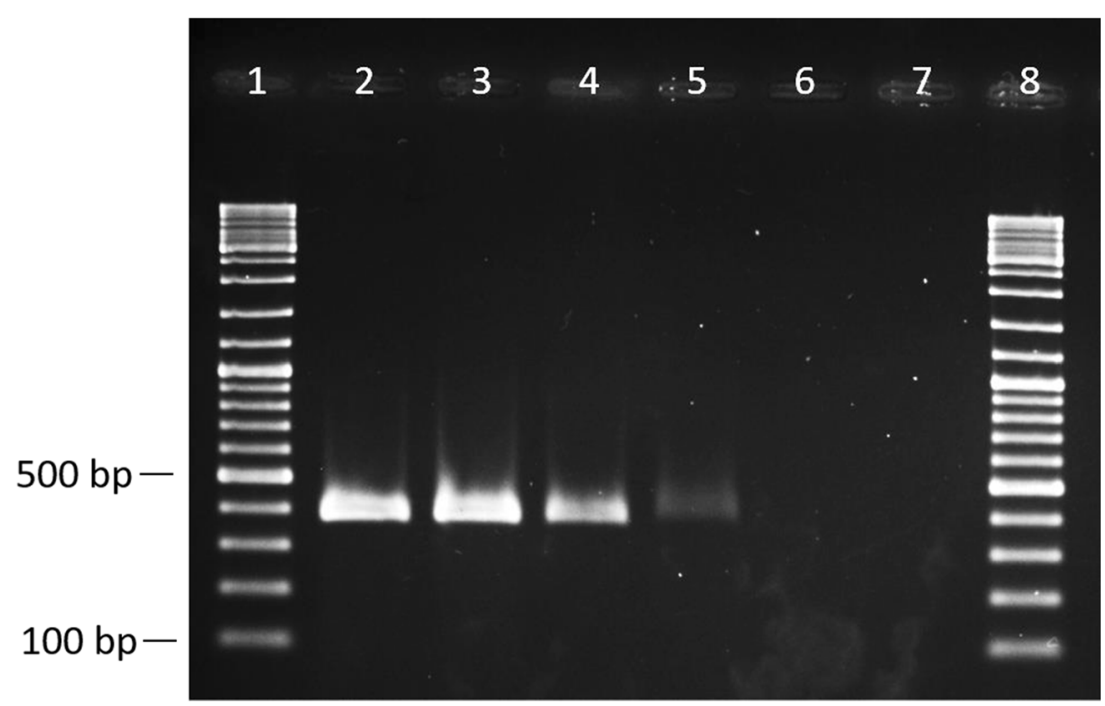

GarVE. Virus-specific PCR primers were designed using an alignment of all cDNA sequences of the coat protein and nucleic acid binding protein genes on the NCBI Nucleotide Database: GarVE-F (5'-GTCCAGGAAAGGCTACCA-3') and GarVE-R (5'-AGYCTACGTAATTTACATTCAGT-3'). Total nucleic acids were extracted from lyophilized leaf tissue using a BioSprint 15 Plant DNA Kit (QIAGEN) as per the manufacturer's instructions, except that RNase enzyme was omitted from buffer RLT. Extracts were tested using a MyTaq ${ }^{\text {TM }}$ One-Step RT-PCR Kit (Bioline Meridian Bioscience, Memphis, USA). Direct Sanger sequencing of the PCR product using the amplification primers was outsourced to Macrogen Korea. All sequence analyses were done using the Geneious Prime version 2020.1.1 software package (Biomatters Ltd., Auckland). Phylogeny was inferred using the Maximum Likelihood method with 1000 bootstrap replicates using MEGA X and uncorrected pairwise nucleotide distances calculated with the same program (Kumar et al. 2018). All isolates were lodged with the DAF Plant Virus Collection.

Four of the forty accessions tested positive for GarVE, based on detection of an amplicon about the expected size of 374 bp (Fig. 1). Virus isolate 5304 from garlic was used as the negative control, which is infected with a single allexivirus, GarVX but not with GarVE. There was no obvious difference in symptoms between plants with and without GarVE because all accessions were infected with multiple viruses from the potyvirus, carlavirus and allexivirus genera and showed clear chlorotic leaf streak symptoms (data not shown). Other viruses also present in the four accessions were: 5308 (LYSV, GarVD), 5327 (OYDV, GCLV, SLV, GarV-A, B, C, X), 5573 (OYDV, LYSV, GCLV, SLV, GarV-A, B, C, X), and 5574 (OYDV, LYSV, GCLV, SLV, GarV- A-D, X) (unpublished results). All amplicons were sequenced (GenBank accession numbers listed in Table 1) and when searches of the NCBI RefSeq database were done using BLASTn, highly significant matches were obtained to the exemplar isolate of GarVE, with nucleotide sequence identities of 97.9-98.5\% over the entire length of the amplicon sequence (partial coat protein (241 nt) and nucleic acid binding protein (95 nt)). The criterion for demarcation of different allexivirus species is $72 \%$ nucleotide sequence identity within either the coat protein or replicase genes (Kreuze et al., 2020). The sequences of all Australian virus isolates were closely related (99.1-99.7\% nucleotide identity) but each was unique, differing from one another by one to three nucleotide substitutions. Phylogenetic analysis showed that the four isolates clustered together with the exemplar isolate of GarVE from China with high bootstrap support (Fig. 2).

To date, GarVE has only been officially reported in China (Chen et al. 2001, Chen \& Chen 2002) and Poland (Chodorska et al. 2013), although there are unpublished
Table 1 List of garlic virus E isolates used for nucleotide sequencing analysis

\begin{tabular}{llll}
\hline $\begin{array}{l}\text { DAF Plant Virus } \\
\text { Isolate Number }\end{array}$ & Cultivar & Garlic Group & GenBank Accession Number \\
\hline 5327 & Glenlarge & Subtropical variety & LC480303.2 \\
5573 & AVRDC accession VFTA287M7 & Subtropical variety & LC480302.2 \\
5574 & Glenlarge & Subtropical variety & LC542632.1 \\
5575 & Glenlarge & Subtropical variety & LC542633.1 \\
\hline
\end{tabular}


Fig. 2 Phylogenetic tree showing the relationships of the Australian isolates of garlic virus E (GarVE) with those from other countries, based on the partial coat protein and nucleic acid binding protein sequences (336 nt). The phylogeny was inferred using the Maximum Likelihood method implemented with MEGA X; bootstrap values from 1000 replicates are shown in the nodes of the branches. The symbol $\bullet$ designates the Australian virus isolates, $\mathbf{m}$ is the exemplar isolate of GarVE, and $\boldsymbol{\Delta}$ is the outgroup, which is garlic virus $\mathrm{D}$ (GarVD)

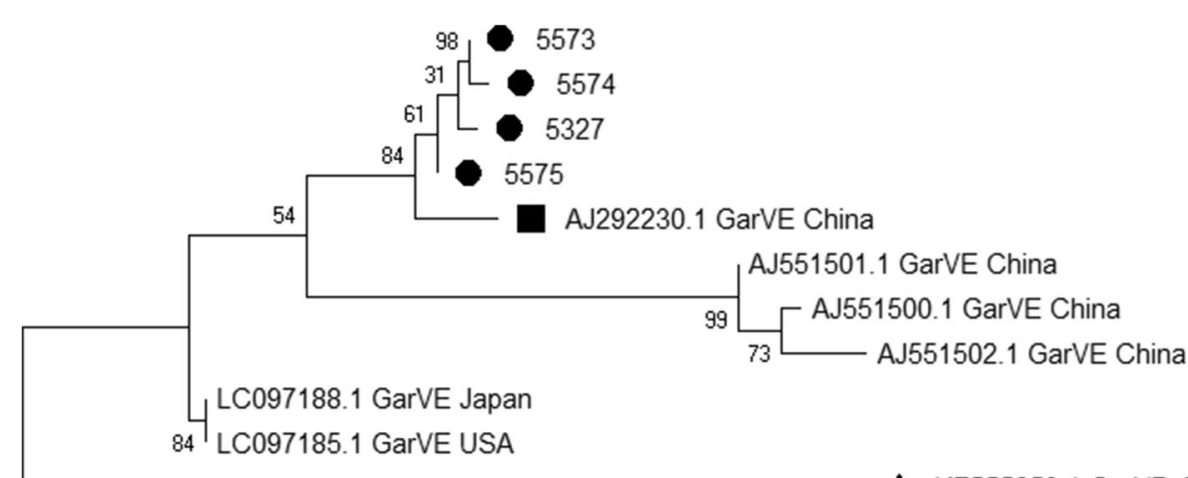

KF555653.1 GarVD Argentina sequences of this virus from the USA and Japan that have been deposited on GenBank (LC097185.1 and LC097188.1, respectively). Hence, our records represent only the fifth country record, although it is expected that the virus is more widely distributed. It was not possible to attribute specific symptoms or yield loss to GarVE, as the plants were also infected with several other viruses. Additional surveys are required in commercial plantings, especially of cv. Glenlarge, which is the dominant local Queensland variety, to determine if the virus is more widespread within the garlic industry.

Acknowledgements This study was supported by ACIAR Project SMCN/2009/056 "Sustainable Productivity Improvements in Allium and Solanaceous Vegetable Crops in Indonesia and Sub-Tropical Australia".

\section{References}

Chen J, Chen J (2002) Genome organization and phylogenetic tree analysis of garlic virus E, a new member of genus Allexivirus. Chin Sci Bull 47:33-37. https://doi.org/10.1360/02tb9006

Chen J, Chen J, Adams MJ (2001) Molecular characterisation of a complex mixture of viruses in garlic with mosaic symptoms in China. Arch Virol 146:1841-1853. https://doi.org/10.1007/ s007050170037

Chodorska M, Paduch-Cichal E, Szyndel MS, Kalinowska E (2013) First report of garlic virus D, E, and X on garlic in Poland. J Plant Pathol 95:69. https://doi.org/10.4454/JPP.V95I4.007
Geering ADW, Mctaggart AR (2019) Questions surrounding the taxonomic validity of the species garlic mite-borne filamentous virus (genus Allexivirus). Arch Virol 164:2367-2370. https://doi.org/10. 1007/s00705-019-04333-7

Katis NI, Maliogka VI, Dovas CI (2012) Viruses of the genus allium in the Mediterranean region. In: Loebenstein G, Lecoq H (eds) Advances in virus research, vol 84. Academic Press, London, pp 163-208

Kang SG, Koo BJ, Lee ET, Chang MU (2007) Allexivirus transmitted by eriophyid mites in garlic plants. J Microbiol Biotechnol 17:18331840

Kreuze JF, Vaira AM, Menzel W, Candresse T, Zavriev SK, Hammond J, Report Consortium ICTV (2020) ICTV virus taxonomy profile: Alphaflexiviridae. J Gen Virol (In Press) 101:699-700

Kumar S, Stecher G, Li M, Knyaz C, Tamura K (2018) MEGA X: molecular evolutionary genetic analysis across computing platforms. Mol Biol Evol 35(6):1547-1549. https://doi.org/10.1093/ molbev/msy096

Sward RJ (1990) Lettuce necrotic yellows rhabdovirus and other viruses infecting garlic. Australas Plant Pathol 19:46-51. https://doi.org/10. 1071/APP9900046

Wylie SJ, Li H, Jones MGK (2012a) Phylogenetic analysis of Allexiviruses identified on garlic from Australia. Australas Plant Dis Notes 7:23-27. https://doi.org/10.1007/s13314-011-0038-2

Wylie SJ, Li H, Saqib M, Jones MGK (2014) The global trade in fresh produce and the vagility of plant viruses: a case study in garlic. PLoS One 9(8):e105044. https://doi.org/10.1371/journal.pone.0105044

Wylie SJ, Luo H, Li H, Jones MGK (2012b) Multiple polyadenylated RNA viruses detected in pooled cultivated and wild plant samples. Arch Virol 157(2):271-284. https://doi.org/10.1007/s00705-0111166-x 